\title{
Are We Silent or Silenced? A Case Study of Working Mothers
}

\author{
Nyla A. Ansari \\ Dr Amanat Ali Jalbani
}

\begin{abstract}
This paper argues for a rhetorical approach to understand how teachers (working mothers) construct silence (resistance or acceptance) in their multiple identities, when academic decisions are taken in meetings that directly affect them and their work. This cross-sectional case study examines arguments for and against a structural change made in an educational institution for girls in Karachi, where $80 \%$ of the population is female faculty. The objective is to present how certain constructions (arguments) are made real while others are undermined as a rhetorical achievement through persuasive talk. Rhetorical analysis was chosen to expose the link between identity construction and silence, through rhetorical strategies drawing on local and cultural discourses with language as a unit of analysis. Since rhetoric is a study of argumentation and persuasion; its application to organizational studies may help the researcher to emphasize over its political functions and understand the language in a critical perspective. Semi-structured interviews with 12 respondents, for an in-depth analysis turned out to be the most effective technique for collecting such data.
\end{abstract}

Keywords: Silence, resistance, identity, working mothers, rhetoric.

\section{Introduction}

\subsection{Background of research}

Olsen et al., (1995) advocates for the importance of teachers' perceived control regarding their career development, their high degrees of autonomy and the challenge they take from their work. Therefore, teachers may form an essential part of the decision-making process due to their indepth involvement not only with their teaching courses, but also in the planning and organization of their teaching strategy.

However, as against this ideal scenario, in Pakistan, where more women prefer to be in this profession; they see themselves as lacking in a voice of authority among their colleagues (Aisenberg and Harrington, 1988). They also report that the difficulties and time constraints in balancing their professional careers with their personal and family lives are more problematic for them than for their male colleagues and put them at a disadvantage within their departments. As a result, they describe themselves as contextually weak and hesitant to voice their concerns at work, with a fear of losing their jobs or chances for promotion. However, this may not be the case with all professional women including teachers. These issues need to be understood in their local (micro) and cultural (macro) contexts, called discourses.

College for women was established in 1990s in Karachi. The number of students currently enrolled has increased to approximately 3000 and the teaching staff stands at an impressive 140 . Micro level discourse in this study refers to the interview context where the relationship between the researcher and the respondent will influence the researcher's interpretation of data. However, such analysis cannot escape its broader organizational and cultural contexts. Thus macro or grand discourses include immediate environment of educational set-up comprising colleagues, the college strategy, its functioning, mission, working conditions and relationships within the faculty and between the faculty and the management.

Nyla Aleem Ansari is a lecturer at IBA, Karachi, aleem_naila@hotmail.com

Dr Amanat Ali Jalbani is Vice President Academics and Dean of Management Sciences at SZABIST, Karachi, jalbani@szabist.edu.pk 
The macro-level context also refers to the effects of cultural discourses on working mothers' identities, roles and positioning in a work setting. In a male dominated society with a hierarchical family structure in Pakistan, where decision powers vary with age and headship, even among women (Alavi, 2003; Ferdoos, 2005); working mothers are often expected to be professional, a responsible wife, an active mother and above all, a qualifying and an obedient social figure in a society where usually high levels of women independence are indicative of their suspicious character and critical reputation. Consequently, they struggle to maintain this image by justifying their roles in one relationship, while asserting the same in another with a complete disregard of what they want for themselves or at least what should be appropriate for them.

\subsection{Problem statement}

The top management (comprising majority male members) and the principal (female) have added Saturday as a $6^{\text {th }}$ working day, with added responsibilities for faculty, with an argument to improve quality education. The interesting part is that resistance is not evident in the form of 'voice'; rather it has led to low morale, fake sick leaves and internal conflict within departments. As against the resistant, there are others who are more committed to this change, adding more to their organizational citizenship behavior and high morale. Being part of this organization in the past, I could easily reflect upon the seriousness of the issue resulting in frustration, impeding creativity and reducing self efficacy of the faculty members.

\subsection{Research objectives}

1) To examine the arguments for (acceptance) and against (resistance) change justified through identity construction of working mothers.

2) To understand how through local and cultural discourses, certain arguments are undermined while others are constructed as 'real' as rhetorical achievements.

3) To understand the function of silence in an educational context.

4) To make explicit, the phenomenon of identity conflict that challenges working mothers in a work situation-an implicit and a taken for granted issue in a Pakistani society.

\subsection{Research question}

To address how working mothers construct silence (as resistance or acceptance) in their multiple identities for and against the change (6 working days) made at work, the following questions served as contexts for arguments:

1. What are multiple identities of working mothers?

2. What discourses have positioned them to compete for their identities?

3. What political functions do such constructions serve in an educational setting?

\subsection{Significance of this research}

This case study explores justifications of silence towards change constructed by working mothers through talk in an interview context in a Pakistani educational setting. The post-modern paradigm may help analyze silence of respondents as forms of resistance and acceptance, in their struggle to compete for their multiple identities at work, regulated by organizational and cultural discourses; rather than understanding silence as an internal and individualized reaction. 


\subsection{Research Methodology}

The research question was developed on the basis of the problem statement of the chosen institution and the literature review available on research topic. The paradigm selection preceded the research question in this case, due to preference of a qualitative design in a social constructionist metaphor. A postmodern (qualitative) researcher's emphasis is on 'transfer' rather than on generalization (Guba and Lincoln, 1994); therefore a (small) sample size of 12 through stratified sampling (Hussey and Hussey, 1997) was chosen for this study. Three strata comprising seniors (with 11-15 years of experience), mid career employees (5-10 years), and new entrants (0-4 years) were considered.

Semi-structured interviews of one to two hours at a venue of the respondent's choice were carried out in this study. An interview guide served the purpose to stay focused on the main topic due to emerging themes during the interview process. Rhetorical analysis by Michael Billig (1996) was used as a method to analyze and 'interpret' the data collected through interviews Language was selected as a unit of analysis to support the proposed paradigm and research question. The participants positioned me both as a 'participant' (due to similar profession and gender) as well as an 'independent and trustworthy' researcher to enable freedom of expression and representation in research.

\subsubsection{Paradigm}

According to Guba and Lincoln (1994), paradigms are defined as a set of beliefs that one may hold to position him in the world, the world's nature itself and the relationships that he may engage in the domain constructed by him. To examine how participants take positions to present constructions of silence in a dialogic and persuasive mode through arguments for and against change; a social constructionist approach (Dick and Nadin, 2006), oscillating between the critical and the postmodern paradigm, (where discourses are used to argue and persuade the audience) was selected to address this phenomenon.

\subsubsection{Social Constructionism}

Social constructionism accepts that all forms of knowledge are human constructions in specific contexts, and that we make choices on the basis of our critical judgment and personal preferences in our social contexts. It rejects the idea of accepting specific discourse as an objective truth and advocates for possible alternatives for adoption. ((Dick and Nadin, 2006).

\subsubsection{Language}

Foucault (1977) suggests that discourses are meant for seizing power through language; it can reveal how people take positions in constructing realities in discursive practices and influence others' opinions, beliefs and behaviors. As explained by Cazden (1988), language builds social relationships and communicates attitudes and identities of speakers; hence it is a social practice. Since words can have different meanings in different cultures, their 'use' in language (Wittgenstein, 1953) will be context and culturally bound, understood through a dialogue that leads to 'new-shared grammar' (Stevenson and Beech, 1998). As a result, an opportunity to cocreate new possibilities for action (Anderson and Goolishian, 1992), will lend a full support to Wittgenstein's 'emergent-rule language games,' where interaction between the researcher and respondent will uncover knowledge underpinning the existing truth claims.

\section{Literature review}

\subsection{Change management}

According to Kirkpatrick (2001), one of the most important reasons for resistance to change is the lack of participation of those who are involved in a change, as they feel ignored and unworthy of 
decision making ability as perceived by their superiors. Corsun (2000) urges for participation of those individuals in decision-making who are directly responsible for its implementation, as in their absence, inappropriate choices for them may lead to misrepresentation of their perspectives and consequently produce resistance with such decisions. Change management is a very wide field and therefore it is essential to narrow down the issues that are relevant to this study. This study (through literature) focused specifically on theories of silence, resistance and stress to understand identity construction of working mothers in a change situation.

\subsection{Stress}

Stress can be defined as a situation when human beings face events that are perceived by them as dangerous, either physically and psychologically (Atkinson, Smith, Bem and Nolan-Hoeksema, 1996). Kenyeri (2002) specifically mention time spent at work and school policies as important determinants of teacher's well-being and improved work environment, whereas Capel (1986) highlights role ambiguity and role conflict as teacher' stressors in the domain of decision-making. There is an emerging agreement on the idea that ineffective policies like long working hours and lack of decision latitudes will act as stressors for employed mothers, suggesting flexible working hours and family friendly policies, to reduce the effects. However, Kinman and Jones (2005) suggest that stress needs to be understood in its cultural context.

\subsection{Silence as a form of acceptance}

According to Glen (2002), silence is perhaps the most undervalued traditionally feminine rhetorical site. He also asserts that sometimes women choose to be silent in certain situations for different reasons. Morrison and Milliken (2000) view silencing conflict as a persistent phenomenon in many organizations, when an individual perceive a difference with another he often do not fully express himself. Organizations often develop cultures of silence based on shared assumptions that it is inappropriate to bring up one's differences. They also see inheritance of emotional and cognitive mechanisms that motivate individuals to avoid perceived risks to their psychological and material well-being.

Silence is a feminist issue where women have been silenced throughout history, and their voices have been denied validity. Whilst silence can disempower people, it can be more powerful than speech.

\subsection{Silence, resistance and identity in a postmodern perspective}

Changes are not always welcome in organizations and therefore resistance to change is an expected outcome of this process. According to Symon, G (2005), in the domain of psychology, this phenomenon remains unproblematic because resistance is explained as an individual and an internal reaction. From a sociological perspective, resistance is described as a product of class struggle: the dialectic of worker resistance and managerial control. Resistance therefore may be expressed as a collective reaction, a strike or sabotage. This 'traditional' analysis has been criticized for its assumption of resistance as a universal class struggle; and it is suggested that resistance may be understood within specific contexts. Recent approaches to understanding individuals' responses to their positions and roles have utilized post-structuralist conceptions of subjectivity.

Subjectivity is a term used to describe, how in power relations, a person becomes a subject and ties himself to his own identity by self knowledge. Thus identity refers to the individual's selfunderstanding as constituted through the regulatory effects of power/knowledge relations. Therefore power is the key to understanding the ways that individuals come to view themselves, and their relation to their work and work relationships, and Identity is understood as the site of discursive struggle, where different discourses compete to fix the individual's identity. Discourses are regulated statements that define norms to regulate social objects and as they are dynamic, they provide more subject positions for people to take up. As people struggle to construct an 
identity in these discourses, resistance is produced. Resistance specified here does not mean an obvious denial or an expressed resentment, rather it is how individuals position themselves within different discourses, take up identities offered and engage in related practices. Since power can also be defined as silencing of voices, therefore both 'resistance' and 'compliance' can be understood as silence.

\subsection{Rhetoric}

There is a growing interest in the study of rhetoric and argument in organizations (e.g. Watson, 1995). Rhetorical analysis has focused on different elements of organizational life including employment relations (Hamilton, 2001), management consultancy and management fashions (Case, 1999) and computer-supported cooperative work.

According to Gill and Whedbee (1997) rhetoric has two aspects; (1) that the essential activities of rhetoric are located on a political stage; and that 'rhetoric is a discourse estimated to influence an audience toward some objective. Therefore, when rhetorical approaches are used to study organizational discourse, the focus is to understand certain political functions they may serve. Therefore a researcher may critically evaluate language in a social context.

Both Shotter, in his 'rhetorical-responsive version of social constructionism' (1993) and Billig (1996) argue that rhetoric is dialogical. In other words, arguments are produced that may be undermined through counter-arguments. According to Potter (1996) there are two particular forms of rhetorical talk: 'reifying', that which seeks to convince us that accounts are facts; and 'ironizing', that which seeks to expose those 'facts' as a social construction (Potter 1996). Thus, individuals try to persuade an audience that a particular social construction is real, while simultaneously seeking to expose other constructions as untrue.

While the rhetorical approach has very different roots (i.e. in the art of rhetorical speaking associated with ancient Greek philosophers (Billig, 1996), it also has similarities with the microdiscursive approaches of Foucault (1982). However, Rhetorical analysis does not assume particular Discourses, nor does it focus on how such discourses operate in defining subjectivity or provoking resistance (Fournier 1998). The focus is on argument and counter-argument (resisting reality constructions) and rhetorical strategies for achieving these, and the interest is in how different types of discourses are used to pursue a particular argument in a dynamic and political way. Identity construction (as a particular 'reality') is an important element of this process.

\subsection{Feminist theory}

Authors of feminist interpretations not only draw our attention back towards the importance of the role that public life plays in the well-being and freedom of women but also provides us with the language and concepts to reshape public life, so as to empower women in their own capacities as both private individuals and citizens. According to Carole Pateman (1988), contracts such as marriages, employment and prostitution, usually constructed as metaphors of freedom and voluntarism are always relations of domination and subordination in reality. Thus the worker is not only exploited under the wage contract; he is also subordinated to the capitalist.

She specifically criticizes the traditional political theory that implicitly excludes women as independent individuals in a patriarchal society, where women will always be subordinate to men. She likes to develop a new political theory or a conception of life where women participate in public life to the full and yet retain their identity as women However, Adman, P. (2008) has challenged Pateman's theory of 'increased participation theory (Pateman, 1970) at work place leading to more autonomy and effective political participation.' Adman's research findings lend no empirical support to this theory and suggest that the effects of this study may have been overestimated due to its cross-sectional nature and methodological weaknesses. 


\section{Data Analysis and interpretation}

Rhetorical analysis by Michael Billig (1996) was used as a method to analyze and 'interpret' data collected through interviews - the most valid and convincing means to gain an in-depth analysis that was transcribed and produced as text for analysis The specific version of rhetorical analysis chosen for this case study is based on a micro-discursive practice with a focus on 'talk' in the 'interview context' drawing on cultural and organizational discourses (Foucault, 1982).

A regular contact with the participants was maintained to ensure a continuous review of data interpretation for its internal validity. A mutual contract was signed to document concerns of anonymity and consent of the participants to support this study. The argumentative contexts constructed through interviews, in this case include whether or not Saturday as a working day was useful to the organization, whether this change was implemented in a satisfactory manner and what are the effects of this change at work.

The interest of this study lies in understanding the functions of silence as forms of resistance and acceptance of the change, as a demonstration of identity constructions through talk. In both cases, the faculty is not speaking up, described as silence. It was in the interview context that some of the faculty members were conveying their grievances but would not voice them before the management. The others were justifying their acceptance and thus remained silent.

Excerpts from interviews are presented below. Rhetorical strategies used by the respondents emerged as themes of identity, silence, change and gender during the interviews. To save reading time and stay with the word limit, only those responses have been documented that best represent the majority opinions of a faculty member group for a particular question.

\subsection{Construction of resistance and identity}

Question: How do you make sense of this additional working day?

Senior faculty: "Yes, it is an effective way to improve quality education, especially for the junior staff with no experience... Actually they do not like this change as it seems to take away their time they need for other activities. Though they are new and young, but will settle down with us, and of course we are all here for them!

Here resistance is presented as personal and an individual reaction of the junior staff whose identity is constructed as someone who is disinterested and has less knowledge about her work. Another construction of the resistant points to their 'other life', most probably their home life, that is undermined and constructed as a weakness due to their comparatively more involvement at home as they may be newly married and have very small children. The last statement in the quote clearly places the seniors as more capable and experienced to shoulder the responsibility not only to motivate the young, de-motivated staff to follow them but also to promote their organizational citizenship, commitment and loyalty to the organization. Hence acceptance (silence) about this change is legitimate and authentic, while resistance as silence is depoliticized against the collective voice against change.

Question: So you think Saturday is the best alternative to improve standards of education?

Another senior teacher: "Management always thinks in the best interests of its people, and if everyone is consenting to this, then I think it will work...especially the newly hired will develop more. They should take this change positively."

This construction again uses the discourse of collective and justifies silence as an accepted change on an organizational scale. Also, there is a construction of respect for authority as final, irrespective of being right or wrong. Implicit in this argument, the middle career professionals are 
constructed as part of the collective-high achievers; as they are very close to reap fruits of their long services through fringe benefits offered by the organization.

Question: Do you see any improvement after this change?

A counter-argument by a few junior teachers: I believe, some "teachers" prefer this style of working, writing diaries, lesson plans and papers checking on the premises. But that's not the only way to organize as a "lecturer." I mean I do most of my work on the computer... then I can give enough time to my home...

A dichotomy of teaching is being created here, where style and standard of work is different for a teacher, (could be of a school) from that of a lecturer asserted here as someone more competent, comparatively, who can manage work efficiently. Simultaneously a construction of a young working mother identified with a lecturer is reified here, who needs to maintain a balance of work and life, thus undermining the argument (earlier presented), as obsolete.

However the interview with the middle career staff demonstrates entirely a different construction of reality.

Middle career faculty: "It's a big change though, but we are committed, no matter what! You don't get jobs like these that pay you well and offer a decent place to work."

It is a different world of change for the experienced, competent and yet younger faculty, where they may have aspirations of their own to climb top positions, reap organizational benefits, yet juggle with home and work to keep their socially acceptable jobs at a stage when they will benefit the most. However, using the phrase, 'it is a big change' does indicate that they and their expertise have been challenged, when they could and had been managing well in the past. Therefore again, silence as acceptance has been justified. A construction of a weak gender and social status is being presented here. 'No matter what', reflects their acceptance of the decision without their involvement in it. There is a clear element of fear of losing their job or chances of promotion if they speak up.

\subsection{Effects of change}

A counter-argument by the researcher:

Question: But extra hours at work do make you efficient?

Senior faculty: "But this change is not looking into the big picture... how earned leaves are being used more frequently than before. Besides, there is a waste of electricity, transportation, cafeteria and other resources."

A very different counter-argument was made by a few seniors, to persuade the researcher, where identity of a senior was promoted safely as someone responsible and committed to organization and concerned about its waste of resources, yet a concern was expressed for the others (could be mid or early career staff) who were having (personal) problems; constructing them as less dedicated to their jobs.

Mid-career faculty: "We just need to organize well at home, as the children are off... This does create discomfort at home."

This is another ambivalent form of silence both as resistance and acceptance of a change. The identity of a working mother is demonstrated as an under-pressured married woman whose work priority diminishes the most when her family is home. The extra day does not seem to challenge her to come to work; rather it is a conflict of multiple identities that may challenge her identity in a professional (organizational) discourse. 
A casual response representing juniors: "It depends, how the time is utilized. A quick fix model will not make us effective."

In this case the confidence of the juniors undermines the efficiency argument. Moreover, the rationale behind change is undermined by constructing it as something rigid and unchangeable even if it is not useful. This response also indicates resistance by the junior staff to a created discourse of a change which challenges their positioning in the professional discourse.

\subsection{Administration-Faculty Divide}

Question: Do you think administration thinks best?

A counter-argument by a mid-career faculty was: Probably they want us to improve, but the strategy needs to be matched to the nature of job. We do listen to them obviously, as we cannot afford to risk our careers...

This statement points to the marginalization of faculty members by excluding them from participation in decisions as a boundary is drawn between authority and responsibility , the former being the right of the top management, while the faculty is burdened with implementing the decisions. Regarding the match between the strategy (plan) and the nature (teaching), an argument is made about the importance of teachers' participation in decisions as they are the ones who know what is right for students and the teachers in practice. But the last line counters the argument made above, by constructing a confused identity of a professional and a home maker by justifying their silence to accept decisions to save their jobs, as speaking up will put them in trouble. Hence again homemaker discourse takes the lead undermining their professional identity.

Question: How was the decision made?

Mid-career faculty: "We were informed of this decision through a circular that mentioned the time and date to make it clear to everyone."

A counter-argument by the researcher:

Question: So you were informed in writing and things were clear?

Mid-career: "Yes, but we were informed and not consulted though... there could be more debate on this, but decisions over here are centralized and it is not only one college or school that we are talking about. But they must understand that it has women as its major work force."

In the first excerpt, there is an explicit reply to the question with an assumption that 'we' (faculty) are quite familiar with this (dominant) style of communication, where the administration expects the faculty to comply with orders that are documented. But as the second question challenged the assumption of learned helplessness, withdrawal and silence of the respondent; cultural and organizational discourses were utilized very tactfully to persuade the researcher that the social construction is real and due to ineffective leadership, gender bias and centralized decisions, such decisions are imposed on them without considering the contextual demands of professional women.

Another counter-argument by the mid career faculty:

In the same vein, a discourse of "board composed of men" constructed a case for ignorance of women's concerns. The legitimacy of the board decision is further undermined by expressing a disappointment over an unfair decision that did have women (as heads of institutions) in the board. 
"Gentlemen have the time and interest to sit long hours. But they must realize that they are dealing with women. When we complain to our heads; they advise us to take a long leave or resign!"

Further, an identity of a head is projected as (1) someone with either a denial of working mothers' issues and thus, ignoring the fact on purpose, that this is a (temporary) phase in every married woman's life (including herself) and may not be constructed as a flaw in their career advancement; or (2) some atypical, masculine woman who did not have a home life on her agenda. Here again the professional identity of working mothers is challenged in terms of time and length of service. Since the seniors are more settled in their lives, they are in a good position to spend more time at work, thus qualifying for a status set by the biased board. In addition to this, the early and mid-career faculties are identified as less professional and are directly threatened to take long unearned leaves till their children grow. However, this is a great source of stress for them as they may either need this job or are at a stage in career where length of service may bring them promotions and other benefits of the job.

\section{Conclusions}

Three rhetorical strategies were identified in this analysis to pursue arguments and counterarguments; (1) construction of identities of the resistant, the committed collective and the high achievers; (2) use of discourses (professionalism, teaching, technology, administration) drawing boundaries within the faculty and between faculty and management; (3) cultural discourses of gender bias, hierarchical family structure, the paradigm of male domination and marital status. The strategies are presented in detail:

i. Silence as resistance to change was constructed as an internalized and an unreasonable reaction and therefore, was subverted and made less legitimate; thus presenting the mid and the early career faculty as less professional.

ii. On the other hand, a construction of acceptance by the mid and the early career faculty persuaded the audience (researcher and the management) of a conflict between multiple identities of working mothers at different stages of life and career through the utilization of cultural and gender discourses.

iii. Another argument by the seniors justified change as a function of commitment and respect for authority as final and unquestioned, hence reflecting the culture of the organization and to some extent the constraints of the senior faculty in power relationship with the board members. In addition to this, perhaps, seniors are also defending their position to secure their jobs as they are approaching retirement and do not have much choice.

iv. A dichotomy of identities was an interesting rhetorical achievement in language presented through discourse of 'teaching' distinguishing between lecturer and teacher with different capabilities challenging the efficiency argument of having an additional working day.

v. The discourse of technology, indicating an obsolete way of working (popular among the seniors) that may have reinforced the idea of Saturday, also undermined the significance of change. It is anticipated that seniors ( as constructed by the juniors) who are used to their systematic and manual style of working, and quite adamant in adapting technology, may be the real advisors of this additional working day.

vi. A counter-argument of quick fix model, by the juniors, persuaded the audience of a bureaucratic style of management preferred where instructions are expected to be 
followed without a dialogue, presumed as correct, and impossible to reverse; as it may question the expertise and vision of the top brass.

vii. In another argument by the seniors, waste of resources was directly related to leaves taken by the juniors, undermining the counter-argument against management. Again the juniors' identity was challenged as being less concerned about their work. Somehow this construction is also undermining the juniors' ethical conduct in securing earned leaves through medical certificates and false excuses, ignoring the fact that this occurrence is a result of placing them in a perplexed situation where they are competing for their multiple identities in discourses of work and life.

viii. In this analysis, the discourse of work and life balance was an issue almost ignored both at the administration and senior level-a discourse that could provide a meaningful and a safe reconstruction of the identities of the working mothers. Thus the voice of the inexperienced and career seekers was marginalized through weak marital status and junior-senior divide.

ix. The discourse of administration-faculty was utilized creatively by the junior faculty to politicize a reality of 'denial of agency-silencing of voices' claiming that faculty was excluded from participation in the decision regarding change as they are the real people who must be involved in such decisions. However, such constructions may be undermined by other (senior) faculty members as 'not true' through the discourse of professionalism, where young working mothers may not be able to establish their identity according to the discourse that describes work as a function of time, set procedures, absence of dialogue, rigidity and physical presence.

x. Most surprising finding of this analysis revealed different identities of women serving different political functions in different phases of their life and work. For example, a construction of seniors' identity of being more experienced, having secured jobs and settled family life; was made real. This was surely due to their qualifying status with the professional discourse set by their top managers who were mostly men. On the other hand, the discourses of ' use of leaves', 'time for other activities' placed the junior staff in a weak position to become ineligible for participation in decisions as they were projected to be less professional and unavailable. On the other hand, the discourse of technology and seniority undermined the argument of change supported and probably initiated by the senior faculty, disregarding an alternative approach of computer use offered by the young faculty. It was evident that the discourse of culture and power was creatively utilized to produce arguments for and against changes according to age, position and marital status amongst the same gender-women.

\section{Recommendations}

- It is proposed that in-depth studies on conflicting identities constructed through talk, serving political functions, need the attention of research. It is possible that such constructions may themselves constitute the powerful patriarchal paradigm of domination that both surrender independence and support marginalization of working mothers in pursuit of headship in power relations in life ( hierarchical family structures) and work (senior-junior divide and gender bias). In the absence of such studies, one may only see the smaller picture where male domination is identified as the root cause of problems and hence made real. However, the paradigm of male domination remains one of the most concerted and resolute topic of research in women studies.

- Moreover, since silence was constructed both as a demonstration of resistance and acceptance to change, therefore its ambivalent functions may be understood in specific 
contexts. Resistant attitudes expressed by working mothers may not be considered as an outcome of underlying psychological dispositions, but as products of broader sociocultural discourses in which individuals are positioned. Hence new discourses like family friendly policies, flexible working hours and virtual classrooms can help them create meaningful and secured identities.

- Longitudinal researches are needed to understand the links among participation, resistance and working mothers' roles in work and life to observe the effects such theories. Since age and time in our society strengthens position of women, therefore effects of these elements may be studied on senior, mid-career and junior staff separately.

- Studies of 'voice' may be encouraged to explore theory of silence and its functions in specific contexts.

- Teachers training programs are advised to all faculty members to pick up latest tools of classroom techniques and time management.

- Positive psychology is needed as a social constructive activity for self realization, self management and empathy to be injected as part of a teacher's behavior when interacting with students and colleagues. Staff counselors may be appointed who can both advise and counsel faculty to develop its potentials in this capacity.

- More open conferences and family friendly seminars (that include spouses) may reduce the gap between the work and life domains, where new theories can develop with the help of free ideas, argument and counter-arguments.

- A very significant investment of building trust and confidence is needed to resolve internal conflict to develop this social and intellectual capital of the institution, i.e. Teachers.

An analysis of a working mother's identity construction in an educational context was envisaged here; how "talk" is used as a social construction using local and cultural discourses to resist or accept change as a persuasive (rhetoric) achievement. An examination through 'talk' revealed employees as accomplished rhetoricians and creators of meaning (Symon, 2005). Since this was a study of dialogue, therefore an element of argument may allow possibility of a counterargument and the process may be never ending. 


\section{References}

Adman, Per (2008) Does Workplace Experience Enhance Political Participation? A Critical Test of a Venerable Hypothesis, Political Behavior, 30:115-138.

Aisenberg, N., and Harrington, M. (1988) Women of Academe: Outsiders in the Sacred Grove, Amherst, the University of Massachusetts Press.

Anderson, H. and Goolishian, H. A. (1992) The client is the expert: A not knowing approach to therapy. In therapy as social construction (McNamee S. and Gergen, K.J. eds). Sage, London, pp. 25-39.

Atkinson R. L., Atkinson R. C., Smith, E. E., Bem, D. J., and Nolen-Hoeksema, S. (1996) Introduction to Psychology. (Translator: Yavuz Alagon) Ankara: Arkadas Publishing.

Billig, Michael (1996) Arguing and thinking: A rhetorical approach to social psychology, Cambridge: CUP.

Capel S. A. (1987) The incidence of and influences on stress and burnout in secondary teachers, British journal of Educational psychology, vol. 57, pp. 279-88.

Case, Peter. (1999) 'Remember re-engineering? The rhetorical appeal of a managerial salvation device'. Journal of Management Studies 36/4: 419-441.

Cazden, C. (1988) Classroom discourse: The language of teaching and learning. (Portsmouth, $\mathrm{NH}$, Heinemann.

Corson, David (2000) Emancipatory leadership. International Journal of leadership in Education, Vol 3, no.2, pp. 93-120.

Ferdoos. A. (2005) Social status of rural and urban working women in Pakistan. A comparative study, elib.ub.uniosnabrueck.de/publications/diss/E-Diss561_thesis.pdf

Foucault, M. (1977) Discipline and Punish, London: Allen Lane

Fournier, Yvonne (1998) 'Stories of development and exploitation: Militant voices in an enterprise culture'. Organization 5/1: pp. 55-80.

Gill, Ann, and Karen Whedbee (1997) 'Rhetoric' in Discourse as structure and process. T. Van Dijk (ed.), 157-184. London: Sage

Glenn, Cheryl (2002) "Silence: A Rhetorical Art for Resisting Discipline(s)." JAC 22.2.

Guba, E.G. and Lincoln, Y.S. (1994) Competing paradigms in qualitative research. In N.K. Denzin and Y.S. Lincoln (eds), pp. 105-117, Handbook of qualitative Research. Thousand Oaks: Sage.

Hamilton, Peter (2001) 'Rhetoric and employment relations'. British Journal of Industrial Relations 39/3: pp. 433-449.

Alavi, Hamza (2003) Pakistani women in a changing society . Social culture. Pakistan

Hussey, J and Hussey, R. (1997) Collecting the original data. Chapter 6, (pp 139-181) in Business research. London: MacMillan 
Kinman, G., and Jones, F. (2005) Lay representations of workplace stress. What do people really mean when they say they are stressed? Work and Stress. 19(2), pp 101-120.

Kirkpatrick, Donald (2001) Managing change effectively. Copyright Butterworth-Heinemann.

Morrison, E. W, and F. J. Milliken (2000) "Organizational silence: A barrier to change and development in a pluralistic world." Academy of Management Review, 25: 706-725.

Olsen, D., Maple, S., and Stage, F. (1995) Women and minority job satisfaction: Professional role interests, professional satisfactions, and institutional fit. Journal of Higher Education 66(3): pp. 267-293.

Pateman, Carole (1970) Participation and Democratic theory. Cambridge: Cambridge University Press.

Pateman, Carole (1988), The Sexual Contract: Cambridge; Polity Press.

Shotter, John (1993) Conversational realities: Constructing life through language. London: Sage

Stevenson, C and Beech, I. (1998) Playing the power game for qualitative researchers: the possibility of a Post-modern approach. Journal of Advanced Nursing, 1998, 27(4), pp. 790-797.

Symon, Gillian (2005) Exploring Resistance from a Rhetorical Perspective. Organization Studies Online First, published on September 20, 2005.

Watson, Tony (1995) 'Rhetoric, discourse and argument in organizational sense-making: A reflexive tale'. Organization Studies 16/5: pp. 805-821.

Wittgenstein, L. (1953) Philosophical investigations (Oxford: Blackwell). 


\section{The interview guide}

1. Can you explain how you make sense of "Saturday as a working day?"

2. How was the decision made and how did it affect you?

3. Was this the only way?

(Emerging themes, like; the argument itself that it was meant to improve teaching quality and improved results? Or did that help? Or why it was not helping?)

4. So do you think administration thinks best?

5. What are other ways to solve this issue? 